\title{
Reducing Glypican-4 in ES Cells Improves Recovery in a Rat Model of Parkinson's Disease by Increasing the Production of Dopaminergic Neurons and Decreasing Teratoma Formation
}

\author{
Annalisa Fico, ${ }^{\star}$ Antoine de Chevigny, ${ }^{\star}$ Christophe Melon, Manon Bohic, Lydia Kerkerian-Le Goff, Flavio Maina, \\ Rosanna Dono, $\dagger$ and Harold Cremer $\dagger$ \\ Aix-Marseille University, Centre National de la Recherche Scientifique, Marseille, IBDM, UMR7288, Marseille, France
}

\begin{abstract}
The heparan sulfate proteoglycan Glypican $4(\mathrm{Gpc} 4)$ is strongly expressed in mouse embryonic stem (ES) cells where it controls the maintenance of self-renewal by modulating Wnt/ $\beta$-catenin signaling activities. Here we show that mouse ES cells carrying a hypomorphic Gpc4 allele, in a single-step neuronal differentiation protocol, show increased differentiation into dopaminergic neurons expressing tyrosine hydroxylase (TH) and nuclear receptor related-1 protein (Nurr1) 1. In contrast to wild-type cells, these differentiating Gpc4mutant cells expressed high levels of DOPA decarboxylase and the dopamine transporter, two markers expressed by fully mature dopaminergic neurons. Intrastriatal transplantation of Gpc4 hypomorphic cells into a 6-OHDA rat model for Parkinson's disease improved motor behavior in the cylinder test and amphetamine-induced rotations at a higher level than transplanted wild-type cells. Importantly, Gpc4 hypomorphic cell grafts, in contrast to wild-type cells, did not generate teratomas in the host brains, leading to strongly enhanced animal survival. Therefore, control of Gpc4 activity level represents a new potential strategy to reduce ES cell tumorigenic features while at the same time increasing neuronal differentiation and integration.
\end{abstract}

\section{Introduction}

Parkinson's disease (PD) is one of the most common neurodegenerative diseases. It is characterized by a progressive loss of midbrain dopamine (DA) neurons with a subsequent reduction in striatal DA (Olanow, 1999). Pharmacological treatment with L-DOPA temporarily ameliorates clinical symptoms but induces severe complications, such as dyskinesias (Pearce et al., 2001). Deep brain stimulation, although representing an efficient alternative treatment, can also have side effects (Olanow et al., 2000). Celltherapeutic approaches in diseased humans have so far been based on the transplantation of fetal DA neurons, and clinical studies indicate that transplantation of these cells can induce symptomatic relief

Received June 12, 2013; revised May 6, 2014; accepted May 7, 2014.

Author contributions: A.F., A.d.C., L.K.-L.G., F.M., R.D., and H.C. designed research; A.F., A.d.C., C.M., M.B., and R.D. performed research; A.F., A.d.C., R.D., and H.C. analyzed data; A.F., A.d.C., R.D., and H.C. wrote the paper.

This work was supported by Fondation pour la Recherche Médicale (Equipe FRM), Agence Nationale de la Recherche (ForDopa), Fondation de France (Committee Parkinson), European Commission (IAPP Dopanew) to H.C., FIRB-Mertit-N-RBNE08LN4P-002, FIRB International 2006RBIN062YH4 to A.F., Fondation pour la Recherche Médicale, Fondation Bettencourt-Schueller to F.M., and SATT Sud Est-Accelerator of Technology Transfer, Association France Parkinson, Fondation de France (Committee Parkinson), AFM-Téléthon, COST Action CM1106, and Stemchem to R.D. We acknowledge the France-Biolmaging/PICSL infrastructure (ANR-10-INSB-04-01). We thank G. Luxardi for contribution at the initial stage of this project and G. Millet for technical assistance and the IBDML imaging and animal house platforms.

The authors declare no competing financial interests.

*A.F. and A.d.C. contributed equally to this work.

tR.D. and H.C. contributed equally to this work.

Correspondence should be addressed to either Dr. Rosanna Dono or Dr. Harold Cremer, Aix-Marseille University, Centre National de la Recherche Scientifique, Marseille, IBDM, UMR7288, Marseille, France, E-mail: rosanna.dono@univ-amu.fr or harold.cremer@univ-amu.fr.

A. Fico's present address: Institute of Genetics and Biophysics A. Buzzati-Traverso, CNR, Naples, Italy.

DOI:10.1523/JNEUROSCI.2501-13.2014

Copyright $\odot 2014$ the authors $\quad 0270-6474 / 14 / 348318-06 \$ 15.00 / 0$
(Freed et al., 2001; Mendez et al., 2005). However, immunological, logistical, technical, and ethical difficulties have limited the development and application of this approach (Lindvall, 2012).

Embryonic stem (ES) cells or induced pluripotent stem (iPS) cells, differentiated toward the midbrain dopaminergic fate in vitro, represent an alternative source for cell replacement therapy in PD (Björklund and Isacson, 2002; Kim et al., 2002; Perrier et al., 2004; Arenas, 2010). However, in vitro dopaminergic differentiation has to be finely controlled, and current protocols involving morphogens and drugs are complex and costly (Kriks et al., 2011). Moreover, the risk associated with uncontrolled tissue growth in the brain needs to be abolished (Björklund and Isacson, 2002; Isacson, 2003). Indeed, rodent studies have shown tumor formation after ES cell transplantation (Björklund and Isacson, 2002; Barberi et al., 2003) that was insufficiently reduced by the available differentiation protocols (Barberi et al., 2003) or cell sorting (Hedlund et al., 2008). Therefore, the use of ES cells and iPS cells for therapy in PD remains currently elusive.

The cell surface protein Glypican 4 (Gpc4), one of the most abundant heparan sulfate proteoglycans expressed by mouse ES cells, controls the maintenance of stem cell self-renewal (Fico et al., 2012). Remarkably, downregulation of Gpc4 in ES cells suppressed teratoma formation after grafting into the flank of nude mice. Moreover, ES cells with reduced expression levels for Gpc4 $\left(G p c 4^{g t-1}\right)$ showed increased neuronal differentiation in vitro (Fico et al., 2012).

Here we explore the ability of Gpc4 mutant cells to decrease teratoma formation and improve neuronal differentiation in a PD cell-based therapeutic context. We show that $G p c 4^{g t-1}$ ES cells generate increased amounts of mature DA neurons in vitro. 
A

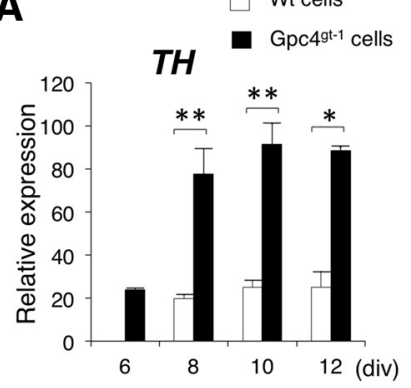

D

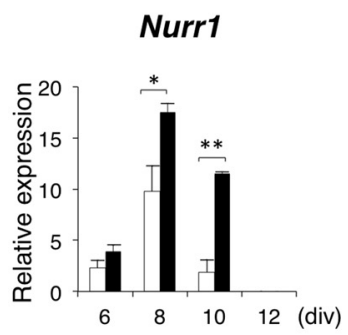

B

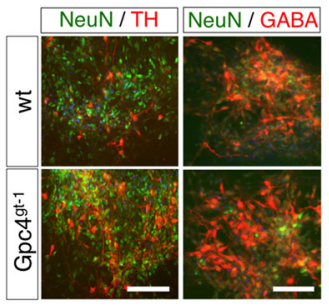

E

$D D C$

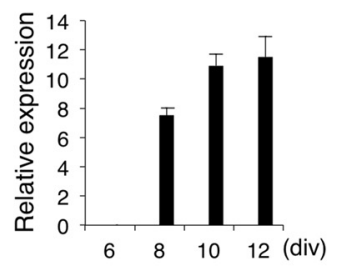

C

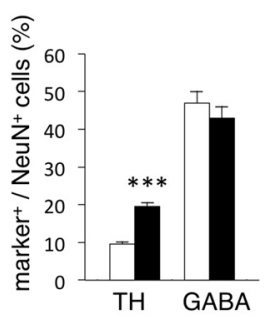

$\mathbf{F}$

\section{DAT}

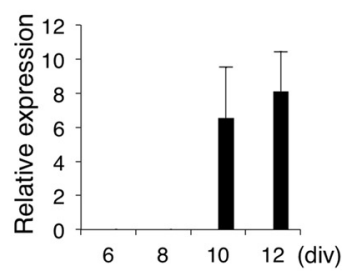

Figure 1. In vitro differentiation of $G p c 4^{g t-1}$ ES cells increases the number of DA neurons. $A$, TH mRNA measured by qRT-PCR at different steps of wt and $G p c 4^{g t-1}$ ES cell differentiation. $B$, NeuN and TH double immunostaining of $G p c 4^{g t-1}$ and wt cultures at 12 DIV. C, Quantitative analysis of the proportion of $\mathrm{TH}^{+}$and $\mathrm{GABA}^{+}$cells among NeuN ${ }^{+}$neurons. Note the significant increase in $\mathrm{TH}^{+}$cells in the $G p c 4^{g t-1}$ condition (wt: $9.6 \pm 0.6 \%$; Gpc $\left.4^{g t-1}: 19.6 \pm 1 \%\right) .{ }^{* * *} p<0.0001$ (Mann-Whitney test). $\boldsymbol{D}-\boldsymbol{F}$, Expression of DA markers at different steps of wt and $G p c 4^{g t-1}$ ES cell differentiation, measured by qRT-PCR. mRNA expression was normalized to GAPDH expression. $n=2$ experiments. ${ }^{*} p<0.05$ (unpaired Student's $t$ test). ${ }^{* *} p<0.01$ (unpaired Student's $t$ test). Scale bars: $B, 100 \mu \mathrm{m}$ (NeuN/TH); $50 \mu \mathrm{m}$ (NeuN/GABA).

\section{A}

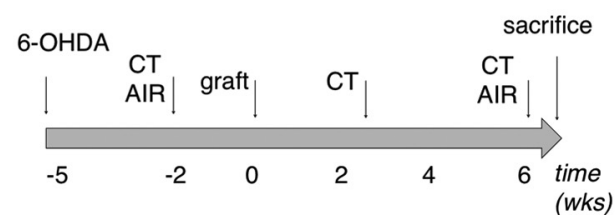

C

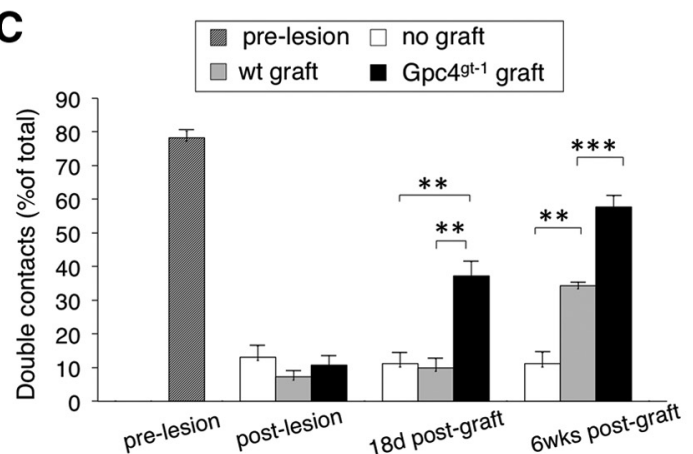

B

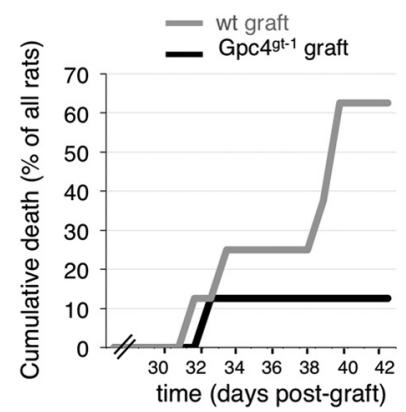

D

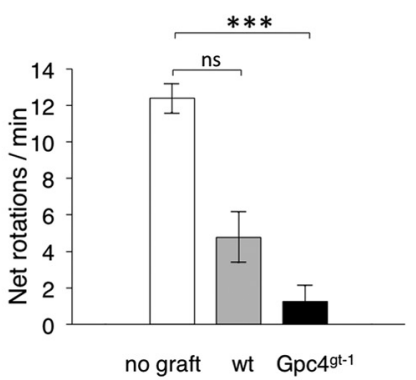

Figure 2. $G p c 4^{g t-1} \mathrm{ES}$ cell grafts result in increased survival and behavioral improvements in parkinsonian rats. $\boldsymbol{A}$, Timeline of the experimental approach. CT, Cylinder test; AIR, amphetamine-induced rotations test; wks, weeks. $\boldsymbol{B}$, Graph reporting the cumulative death of rats after grafting. C, Data presented in the graph are the mean \pm SEM of the double contacts on the wall of the cylinder, expressed as the percentage of the total number of contacts. Note very consistent behavioral improvement in $G p c 4^{g t-1}$ after only $18 \mathrm{~d}$ after cell transplantation. Analyses were performed on $n=7$ animals at time 0 and $18 \mathrm{~d}$, and on $n=3$ for wt graft and $n=5$ for $G p c 4^{g t-1}$ graft at 6 weeks. ${ }^{* *} p<0.01$ (Mann-Whitney test). ${ }^{* *} p<0.0001$ (Mann-Whitney test). D, Amphetamine-induced rotational behavior in sham (no graft, white bar, $n=8$ ), wt graft (gray bar, $n=4$ ), and $G p c 4^{g t-1} \mathrm{graft}$ animals (black bar, $n=9$ ). ${ }^{* *} p<0.0001$ (Kruskal-Wallis test). ns, not significant.

After transplantation of these cells in a rat PD model, dopaminergic differentiation in vivo was increased and accompanied by improved motor behavior. Moreover, $G p c 4^{g t-1}$ ES cells showed decreased teratoma formation, which correlated with enhanced animal survival.

\section{Materials and Methods}

\section{In vitro experiments}

ES cell cultures and differentiation. ES cell lines PST132 and E14Tg2a were previously described (Niwa et al., 2000; Fico et al., 2012). GFP was inserted in both ES cell lines at the Rosa26 locus by transfecting them with the R26P-SA-EGFPpuro plasmid (Addgene). Puromycin-selected ES cell clones were verified for correct self-renewal and differentiation properties and used as pools in all grafting experiments.

Cell lines were maintained on a monolayer of mitomycin-C-inactivated mouse fibroblasts in the presence of DMEM supplemented with 15\% FBS, $100 \mu \mathrm{M}$ 2-mercaptoethanol, $1 \times$ MEM nonessential amino acids, $2 \mathrm{~mm}$ L-glutamine, $1 \mathrm{~mm}$ sodium pyruvate, and 100 units/ml LIF ESGRO (Millipore Bioscience Research Reagents).

Neuronal differentiation used a serum-free neural induction protocol (Fico et al., 2008).

\section{Immunofluorescence stainings and} cell counts

Immunofluorescence stainings were done as described previously (Fico et al., 2012). Primary antibodies used were mouse anti-NeuN (Millipore, 1:100), rabbit anti-GABA (Sigma, 1:300), and rabbit anti-tyrosine hydroxylase (TH, Millipore, 1:300). Quantitative immunocytochemical analysis was performed on randomly selected visual fields from two independent differentiation experiments. On average, 10 visual fields, at $20 \times$ magnification were acquired and a total of $3000 \mathrm{NeuN}^{+}$cells were counted per experiment.

\section{$R N A$ preparation and $R T-P C R$}

Total RNAs were isolated using RNeasy mini kit (QIAGEN) and reverse transcribed using QuantiTect Reverse Transcription kit (QIAGEN) following the manufacturer's instructions. qRT-PCR was performed using SYBR Green PCR master mix (EuroClone). Primers: TH, sense (s) tgtcacgtccccaaggttcat, antisense (as) gggcaggccgggtctctaagt; nuclear receptor related-1 protein (Nurr1), (s) gcccgatgtgggacgat, (as) tctgctcgatcatatgcgtagtg; DOPA decarboxylase (DDC), (s) gaacagacttaacgggagccttt, (as) aatgccggtagtcagtgataagc; dopamine transporter (DAT), (s) gtgggcttcactgtcatcctca, (as) cccaggtcatcaatgccacga; GAPDH, (s) atggggaaggtgaaggtcg, (as) gggtcattgatggcaacaatatc; no. of cycles was in all cases 30 .

\section{In vivo experiments}

6-Hydroxydopamine (6-OHDA) lesions. Male Wistar rats were lesioned by intranigral 6-OHDA injection as described previously (Oueslati et al., 2007). Lesioned animals were 
selected for transplantation based on their response to amphetamineinduced rotational behavior and asymmetry score in the cylinder test to get homogeneous groups of animals.

\section{Immunosuppression}

Cyclosporine A (10 mg/kg Sandimmun, Novartis) in sunflower seed oil (Sigma, S5007) was injected daily starting $1 \mathrm{~d}$ before surgery.

\section{Transplantation procedures}

For transplantations, ES cells were prepared as described by Björklund et al. (2002). Briefly, the cells were seeded at $5 \times 10^{6}$ cells in the absence of LIF. ES cells did not adhere to the dish but instead formed embryoid bodies. Four days later, embryoid bodies were dissociated with trypsin. 6-OHDA-lesioned animals received injections of $1 \mu \mathrm{l}$ of suspension $(10,000 \mathrm{cells} / \mu \mathrm{l})$ into two sites of the right striatum (bregma: anterior 1.0 $\mathrm{mm}$, lateral $3.0 \mathrm{~mm}$, ventral 5.0 and $4.5 \mathrm{~mm}$ ). Two independent cell transplantation experiments were performed.

\section{Behavioral tests}

Cylinder test was performed as reported previously to assess akinesia-like deficit of the forepaw contralateral to the lesion (Oueslati et al., 2007; Jouve et al., 2010). Lesioned rats were tested for rotational behavior in response to amphetamine ( $4 \mathrm{mg} / \mathrm{kg}$ i.p., Sigma). Behavior was monitored by a computerized activity monitor system and analyzed as described previously (Björklund and Isacson, 2002).

Histological procedures, immunohistochemistry, and cell counting Fifty-micrometer sections were prepared and labeled as described previously (de Chevigny et al., 2012). Antibodies included the following: anti-TH (Aves, 1:1000; or Immunostar 1:1600), anti-GFP (Aves; 1:500), anti-nestin (Aves; 1:1000), anti-DAT (Santa Cruz Biotechnology; 1:100), anti-Pitx3 (gift from Austin Smith, 1:1000), anti-FoxA2 (Santa Cruz Biotechnology; 1:100), anti-calbindin (Millipore; 1:1000), anti-GABA (Sigma; 1:300), anti-serotonin (5-HT) (Immunostar; 1:500), and anti- dopamine D2 receptor (DRD2) (Millipore/Abcam; 1:150; specificity of the antibodies was validated on sections at the level of the substantia nigra). Images were acquired with Nikon macroconfocal or with Zeiss 510 Meta/780 confocal microscopes.

Measures of the three largest graft areas for each animal were performed from Nikon macroconfocal images $(5 \times$ lens, optical zoom $\times 3$ ) using ImageJ. TH cell density was counted semiautomatically using ImageJ on every sixth section for each rat.

Evaluation of FoxA2, Pitx3, calbindin, and DAT expression in $\mathrm{TH}^{+}$ cells was done on $63 \times$ Zeiss confocal microscope. Evaluation of GABA, 5-HT, and DRD2 positive cells was done on $20 \times$ Zeiss confocal microscope

\section{Statistical analysis}

Data are presented as mean \pm SEM. $n$ represents number of animals. Statistical tests are specified in figure legends (Instat software, Graph Pad Software). Differences were considered statistically significant when $p<$ 0.05 .

\section{Results}

$G p c 4^{g t-1}$ hypomorphic ES cell cultures showed increased morphological and immunohistochemical signs of neuronal differentiation in a well-defined $12 \mathrm{~d}$ single-step neuronal differentiation protocol as previously reported (Fico et al., 2008). We further characterized the properties of Gpc4 loss-of-function cells under these culture conditions. $\mathrm{TH}$, the rate-limiting enzyme for the synthesis of DA, was strongly induced (Fig. 1A). qRT-PCR showed that as early as at day 6 of in vitro differentiation, when $\mathrm{TH}$ transcripts were not detectable in wild-type (wt) cultures, mutant cells $\left(G p c 4^{g t-1}\right)$ already expressed TH mRNA. Over the entire analyzed time window, TH expression remained approximately fourfold over controls (Fig. 1A).

The increased expression of TH in mutant cells could arise either from globally accelerated differentiation or from specifically enhanced DA neuron fate commitment. Quantitative anal-
A

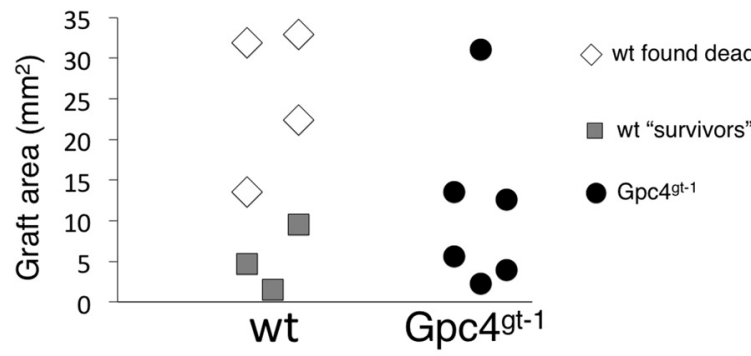

B
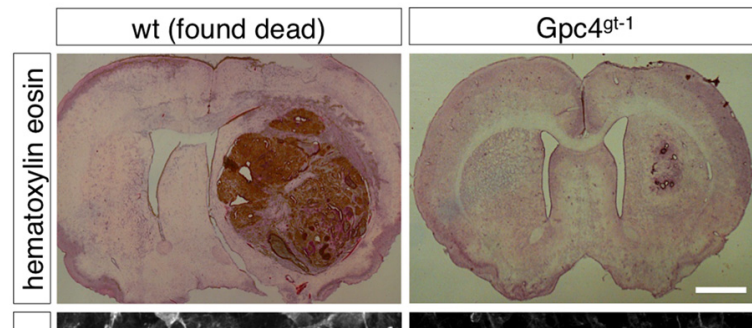

C
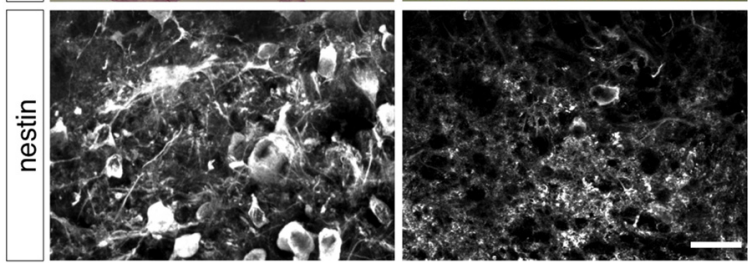

Figure 3. $G p c 4^{g t-1} \mathrm{ES}$ cell grafts do not generate teratoma-like structures in parkinsonian rats. $A$, Graph showing the mean area of wt dead before sacrifice (white), wt survivors (gray), and $G p c 4^{g t-1}$ (black) grafts (in square millimeters). Data were determined from the three largest graft sections. $\boldsymbol{B}$, Examples of hematoxylin/eosin staining of graft sections derived from wt and $G p c 4^{g t-1}$-transplanted animals. wt cells developed teratoma-like structures, in contrast to $G p c 4^{g t-1}$ hypomorphic cells. $C$, Nestin expression was stronger in wt cells than in $G p c 4^{g t-1}$ hypomorphic cells. Scale bars: $\boldsymbol{B}, 3 \mathrm{~mm} ; \boldsymbol{C}, 20 \mu \mathrm{m}$.

ysis at $12 \mathrm{~d}$ in vitro (DIV) showed that in Gpc4 mutant cultures the proportion of $\mathrm{TH}^{+}$presumptive DA neurons among the NeuN-expressing neuronal population was doubled compared with wt cells (wt: $9.6 \pm 0.6 \%$; Gpc $4^{g t-1}: 19.6 \pm 1 \%$; Fig. $1 B, C$ ). In contrast, the proportion of $\mathrm{GABA}^{+}$cells among the $\mathrm{NeuN}^{+}$neurons was unchanged (wt: $46.9 \pm 3 \%$; Gpc $4^{g t-1}$ : $42.9 \pm 3 . \%$; Fig. $1 \mathrm{~B}, \mathrm{C})$. We also stained for parvalbumin and Islet- 1 but found too few positive cells in both conditions to allow for meaningful quantification. Together, these results indicate that Gpc4 loss-offunction promotes the specification toward the DA lineage rather than promoting differentiation globally.

We next analyzed the expression dynamics of midbrain DA neuron markers in Gpc $4^{g t-1}$ cultures. Nurrl displayed increased mRNA levels in $G p c 4^{g t-1}$ cells until 10 DIV and became undetectable at 12 DIV (Fig. 1D), thus showing similar dynamics as in the control situation, but at higher absolute levels. Interestingly, DDC, the last enzyme in the DA biosynthesis pathway, was strongly expressed in $G p c 4^{g t-1}$-derived cultures, whereas wt cells never expressed detectable mRNA levels (Fig. 1E). Finally, the DAT was strongly induced from 10 DIV in mutant cells but not detected in wt cultures (Fig. $1 F$ ). Thus, decreased expression of Gpc4 in differentiating ES cells leads to increased neuronal differentiation (Fico et al., 2012) and a strong shift toward the mature DA neurotransmitter phenotype, even in the absence of factors, such as SHH and FGF8, that are normally added to trigger DA differentiation (Ye et al., 1998).

As $G p c 4^{g t-1}$ ES cells (1) generate mature dopaminergic neurons in vitro and (2) reduce tumor formation after flank trans- 
A

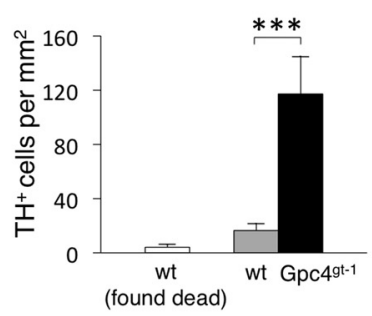

C

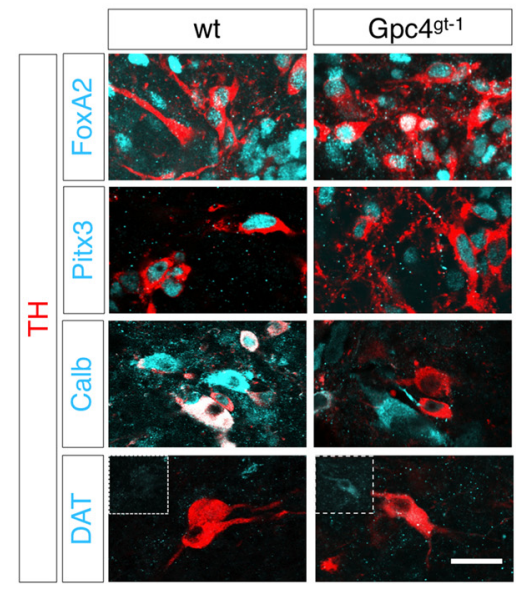

B

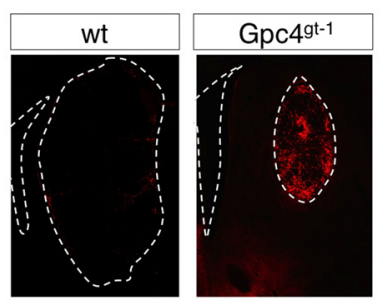

D
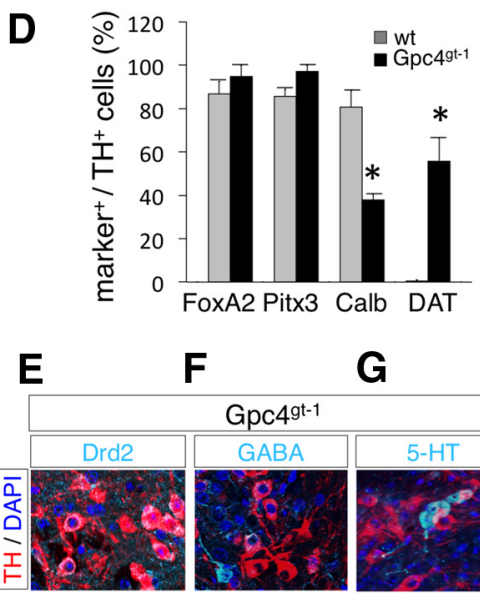

$\mathbf{F}$

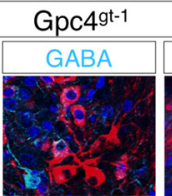

Figure 4. Grafted $G p c c^{g t-1} \mathrm{ES}$ cells generate large numbers of $\mathrm{TH}^{+}$cells with ventral midbrain DA features. $A$, Density of $\mathrm{TH}^{+}$ cells per $\mathrm{mm}^{2}$ revealed that $G p c 4^{g t-1}$ grafts $(n=11)$ contained more DA neurons than wt grafts $(n=6) .{ }^{* * *} p<0.0001$ (Mann-Whitney test). wt-grafted rats that died prematurely (wt dead) showed comparably low levels of TH neurons than survivors. $\boldsymbol{B}$, Representative images of a wt (left) and a Gpc $4^{g t-1}$ (right) graft labeled with TH (red). C, Immunohistochemical characterization of $\mathrm{TH}^{+}$cells in grafts. $\mathrm{TH}^{+}$cells coexpressed some typical midbrain DA neuron markers, both in wt and $\mathrm{Gpc} \mathrm{C}^{9 t-1}$ grafts. FoxA2, forkhead box protein A2; Pitx3, pituitary homeobox 3; Calb, calbindin. D, Percentage of $\mathrm{TH}^{+}$neurons that express also midbrain specific markers. ${ }^{*} p<0.05$ (Mann-Whitney test). $\boldsymbol{E}-\boldsymbol{G}$, Coexpression of DRD2 (E), GABA (F), and 5-HT (G) with TH in mutant grafts. Scale bar, $20 \mu \mathrm{m}$.

plantation in nude mice (Fico et al., 2012), we assessed Gpc4 $4^{g t-1}$ cell transplants in a rodent model of PD. Hemi-parkinsonian rats were generated by unilateral injection of 6-OHDA in the substantia nigra pars compacta. Five weeks later, we transplanted GFPlabeled wt versus $G p c 4^{g t-1}$ ES cells at low doses in the ipsilateral striatum using a embryonic body based protocol (Björklund et al., 2002). To challenge Gpc $4^{g t-1}$ cells, we intentionally chose this minimal protocol because it results in teratoma formation and induces only weak behavioral improvements. At the time of brain transplantation, control and mutant cells still expressed pluripotent cell markers, such as nanog, but no neural differentiation markers, such as nestin (data not shown). Four of seven rats grafted with wt ES cells died within 6 weeks after transplantation, the scheduled endpoint of this experiment. Lethality peaked between 30 and $39 \mathrm{~d}$ post grafting (dpg; Fig. 2B). In contrast, only one $G p c 4^{g t-1}$-grafted animal died before the end of the experiment (day 31; Fig. 2B).

We measured the motor improvements in grafted rats using the cylinder test and amphetamine induced rotation behavior (Björklund and Isacson, 2002). Tests were performed on three groups: nongrafted, wt-grafted, and $G p c 4^{g t-1}$-grafted rats (Fig. $2 C)$. The cylinder test was performed before lesion, after the lesion, and at two different time points after grafting in wt- and $G p c 4^{g t-1}$-grafted rats. In the cylinder test, nongrafted hemiparkinsonian rats lost the ability to use their contralateral forepaw, inducing a dramatic decrease in double contacts on the cylinder walls (prelesioned: $78 \pm 2 \%$ double contacts; postlesioned/nongrafted: $13 \pm 3 \%$ ). At $18 \mathrm{dpg}$, lesioned animals transplanted with wt cells were indistinguishable from nongrafted

G

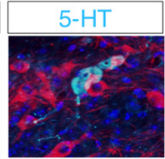

controls. However, at 6 weeks after grafting, use of the left paw improved in this group (nongrafted: $11 \pm 3 \%$; wt-grafted: $34 \pm 1 \%)$. Importantly, rats grafted with $G p c 4^{g t-1}$ cells showed significant improvement already at $18 \mathrm{dpg}(37 \pm 4 \%)$ and the effect further increased, reaching $58 \pm 3 \%$ of double contacts 6 weeks after transplantation (Fig. 2C).

Animals of two independent transplantation experiments were scored for amphetamine-induced rotations at the endpoint of the experiment (Fig. 2D). Analysis of the lesioned/nongrafted and of the lesioned/wt-grafted animals showed no significant change in net ipsilateral rotations, although there was a tendency toward improvement (sham: $12.4 \pm 0.8$ rotations/min, wt-grafted: $4.8 \pm 1.4$ rotations/min; Fig. 2D). Importantly, $G p c 4^{g t-1}$ grafted animals displayed a highly significant reduction in ipsilateral rotations compared with lesioned/nongrafted

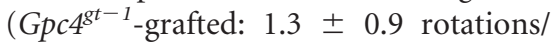
min; Fig. $2 D$ ). In conclusion, transplantation of Gpc $4^{g t-1}$ ES cells in a PD context was associated with strongly decreased lethality and was beneficial for motor functions.

We investigated size and cellular composition of the transplanted tissue. Generally, graft area was smaller in animals that received $G p c 4^{g t-1}$ ES-derived cells, although there was considerable heterogeneity (Fig. 3A). In wt cell-grafted animals, graft area was positively correlated with premature death before sacrifice (Fig. $3 A$ ). In contrast, only one of the Gpc $4^{g t-1}$ ES cell-grafted animals died within 6 weeks of transplantation (Fig. 2B). Hematoxylin/ eosin staining demonstrated that all wt grafts showed the typical morphological array and dense structures indicative of teratomas (Lensch et al., 2007), whereas the Gpc $4^{g t-1}$ grafts showed rather homogeneous morphology and displayed no obvious signs of teratoma-like structures (Fig. 3B). Moreover, expression of nestin, a marker of immature neural cell types (Tohyama et al., 1992), was observed in all grafts, but staining was considerably stronger in wt cells (Fig. 3C). Thus, transplantation of Gpc4 hypomorphic cells strongly limited the occurrence of teratoma-like structures, which were likely the reason for augmented premature death in controls.

We then focused on the $\mathrm{TH}^{+}$cells in the grafts. Importantly, $G p c 4^{g t-1}$ grafts displayed a sevenfold increase in $\mathrm{TH}^{+}$cells compared with wt (wt grafts: $16.5 \pm 5.1$ cells $/ \mathrm{mm}^{2}$; mutant grafts: $117.2 \pm 27.6$ cells $/ \mathrm{mm}^{2} ;$ Fig. $4 A, B$ ). We immunohistochemically characterized the phenotypes of $\mathrm{TH}^{+}$neurons in grafts. FoxA2 and Pitx3, involved in ventral midbrain dopaminergic neuron production (Nunes et al., 2003), were both expressed in most $\mathrm{TH}^{+}$neurons in grafts of wt and $G p c 4^{g t-1}$ origins (Fig. 4C,D). In contrast, calbindin, a protein enriched in ventral tegmental area (Thompson et al., 2005), was decreased in dopaminergic neurons derived from $G p c 4^{g t-1}$ grafts (Fig. $4 C, D$ ), suggesting that dopaminergic neurons in $G p c 4^{g t-1}$ grafts were preferentially of the substantia nigra subtype. Importantly, DAT was exclusively expressed in $\mathrm{TH}^{+}$neurons in $\mathrm{Gpc} \mathrm{g}^{g t-1}$ grafts (Fig. $4 B, C$ ), reminis- 
cent of the in vitro situation (Fig. 1). In addition, most $\mathrm{TH}^{+}$ neurons in the $G p c 4^{g t-1}$ cell grafts coexpressed the DRD2 (Fig. $4 E$; DRD2/(TH + DRD2): $89 \pm 2 \%)$, suggesting that they are capable of autoregulation. Indeed, activation of D2 autoreceptors is known to tune DA synthesis, release, and uptake as well as dopamine neuron firing. Finally, contribution of GABA and 5-HT-positive neurons to the $G p c 4^{g t-1}$ grafts was minor with respect to $\mathrm{TH}(\mathrm{GABA} /(\mathrm{TH}+\mathrm{GABA}): 8.8 \pm 0.4 \% ; 5-\mathrm{HT} /(\mathrm{TH}+$ 5-HT): $11.4 \pm 1.7 \%$; Figure $4 F, G$ ).

In conclusion, decreased levels of Gpc4 increased the level of mature midbrain dopaminergic neurons after transplantation into the dopamine-depleted striatum.

\section{Discussion}

Our data suggest that interfering with Gpc4 expression or function could represent a powerful strategy to increase the efficiency and safety of cell transplantation in PD. Cultured Gpc4 hypomorphic ES cells show a strong tendency to differentiate into cells with properties of mature DA neurons. Moreover, in vivo grafted $G p c 4^{g t-1}$ cells show augmented differentiation into $\mathrm{TH}^{+}$neurons with molecular features of midbrain DA neurons and improve recovery of motor functions in a rat model of PD. Importantly, knockdown of Gpc4 decreases the formation of teratoma-like structures and increases animal survival.

Our data indicate that Gpc4 depletion enhances DA neuron fate commitment in vitro and in vivo. Further studies will clarify whether loss of Gpc4 activity impacts also on the development of other neuronal cell types and whether distinct culture conditions could promote the capability of Gpc4 mutant cells to develop into DA neurons. Mechanistically, glypicans can interact with several signaling pathways, such as Wnt, SHH, FGFs, and BMPs, and they function either as positive or negative regulators of these signaling pathways depending on the cellular context (Galli et al., 2003; Fico et al., 2011). We have recently shown that Gpc4 maintains mouse ES cell self-renewal by positively modulating Wnt/ $\beta$-catenin signaling (Fico et al., 2012). Both the canonical (Wnt/ $\beta$-catenin) and noncanonical (Wnt/PCP) Wnt pathways have been implicated in midbrain $\mathrm{DA}$ neuron generation in vivo (Castelo-Branco and Arenas, 2006). In particular, Wnt5a deficiency induces premature Nurr1 expression and a transitory increase in DA neurons in the ventral midbrain (Andersson et al., 2008). In ES cells, blocking the Wnt canonical signaling increases neural induction and dopaminergic differentiation (Cajánek et al., 2009). Thus, it is possible that fine-tuning of Wnt signaling by Gpc4 might be a regulatory mechanism controlling the generation of midbrain DA neurons in vitro and/or in vivo.

Independent of the mechanisms by which the loss of Gpc4 increases midbrain-like DA neurons, we show that reduction of Gpc4 signaling permits enhancement of DA neuron differentiation from ES cells without adding any exogenous factor, both in vitro and in vivo in a 6-OHDA rat model of $\mathrm{PD}$. Moreover, at the functional level, Gpc4 hypomorphic cell-grafted rats showed strong relief of the lesion-induced motor dysfunction not only in the amphetamine-induced rotation test but also in the cylinder test, a nondrug induced test for akinesia-like deficits that is considered very stringent.

Finally, we find reduced cell overgrowth by Gpc4 hypomorphic grafts. Even the one animal in this group showing a large graft area (Fig. $3 A$ ) showed no signs of teratogenesis and survived until the end of the experiment. This is in agreement with previous work showing that Gpc4 hypomorphic ES cells do not generate teratomas after injection in the flank of nude mice (Fico et al., 2012). Thus, control of Gpc4 may represent a means to reduce
ES cell tumorigenic features while at the same time increasing neuronal features. Because Gpc4 is a cell surface protein, it appears as an attractive target to design drugs that improve security and functional improvement in PD cell therapeutic approaches.

\section{References}

Andersson ER, Prakash N, Cajánek L, Minina E, Bryja V, Bryjova L, Yamaguchi TP, Hall AC, Wurst W, Arenas E (2008) Wnt5a regulates ventral midbrain morphogenesis and the development of A9-A10 dopaminergic cells in vivo. PLoS One 3:e3517. CrossRef Medline

Arenas E (2010) Towards stem cell replacement therapies for Parkinson's disease. Biochem Biophys Res Commun 396:152-156. CrossRef Medline

Barberi T, Klivenyi P, Calingasan NY, Lee H, Kawamata H, Loonam K, Perrier AL, Bruses J, Rubio ME, Topf N, et al. (2003) Neural subtype specification of fertilization and nuclear transfer embryonic stem cells and application in parkinsonian mice. Nat Biotechnol 21:1200-1207. CrossRef Medline

Björklund LM, Isacson O (2002) Regulation of dopamine cell type and transmitter function in fetal and stem cell transplantation for Parkinson's disease. Prog Brain Res 138:411-420. CrossRef Medline

Cajánek L, Ribeiro D, Liste I, Parish CL, Bryja V, Arenas E (2009) Wnt/betacatenin signaling blockade promotes neuronal induction and dopaminergic differentiation in embryonic stem cells. Stem Cells 27:2917-2927. CrossRef Medline

Castelo-Branco G, Arenas E (2006) Function of Wnts in dopaminergic neuron development. Neurodegener Dis 3:5-11. CrossRef Medline

de Chevigny A, Coré N, Follert P, Gaudin M, Barbry P, Béclin C, Cremer H (2012) miR-7a regulation of Pax6 controls spatial origin of forebrain dopaminergic neurons. Nat Neurosci 15:1120-1126. CrossRef Medline

Fico A, Manganelli G, Cigliano L, Bergamo P, Abrescia P, Franceschi C, Martini G, Filosa S (2008) 2-Deoxy-D-ribose induces apoptosis by inhibiting the synthesis and increasing the efflux of glutathione. Free Radic Biol Med 45:211-217. CrossRef Medline

Fico A, Maina F, Dono R (2011) Fine-tuning of cell signaling by glypicans. Cell Mol Life Sci 68:923-929. CrossRef Medline

Fico A, de Chevigny A, Egea J, Bösl MR, Cremer H, Maina F, Dono R (2012) Modulating Glypican4 suppresses tumorigenicity of embryonic stem cells while preserving self-renewal and pluripotency. Stem Cells 30:1863-1874. CrossRef Medline

Freed CR, Greene PE, Breeze RE, Tsai WY, DuMouchel W, Kao R, Dillon S, Winfield H, Culver S, Trojanowski JQ, et al. (2001) Transplantation of embryonic dopamine neurons for severe Parkinson's disease. N Engl J Med 344:710-719. CrossRef Medline

Galli A, Roure A, Zeller R, Dono R (2003) Glypican 4 modulates FGF signalling and regulates dorsoventral forebrain patterning in Xenopus embryos. Development 130:4919-4929. CrossRef Medline

Hedlund E, Pruszak J, Lardaro T, Ludwig W, Viñuela A, Kim KS, Isacson O (2008) Embryonic stem cell-derived Pitx3-enhanced green fluorescent protein midbrain dopamine neurons survive enrichment by fluorescenceactivated cell sorting and function in an animal model of Parkinson's disease. Stem Cells 26:1526-1536. CrossRef Medline

Isacson $\mathrm{O}$ (2003) The production and use of cells as therapeutic agents in neurodegenerative diseases. Lancet Neurol 2:417-424. CrossRef Medline

Jouve L, Salin P, Melon C, Kerkerian-Le Goff L (2010) Deep brain stimulation of the center median-parafascicular complex of the thalamus has efficient anti-parkinsonian action associated with widespread cellular responses in the basal ganglia network in a rat model of Parkinson's disease. J Neurosci 30:9919-9928. CrossRef Medline

Kim JH, Auerbach JM, Rodríguez-Gómez JA, Velasco I, Gavin D, Lumelsky N, Lee SH, Nguyen J, Sánchez-Pernaute R, Bankiewicz K, McKay R. (2002) Dopamine neurons derived from embryonic stem cells function in an animal model of Parkinson's disease. Nature 418:50-56. CrossRef Medline

Kriks S, Shim JW, Piao J, Ganat YM, Wakeman DR, Xie Z, Carrillo-Reid L, Auyeung G, Antonacci C, Buch A, Yang L, Beal MF, Surmeier DJ, Kordower JH, Tabar V, Studer L (2011) Dopamine neurons derived from human ES cells efficiently engraft in animal models of Parkinson's disease. Nature 480:547-551. CrossRef Medline

Lensch MW, Schlaeger TM, Zon LI, Daley GQ (2007) Teratoma formation assays with human embryonic stem cells: a rationale for one type of human-animal chimera. Cell Stem Cell 1:253-258. CrossRef Medline 
Lindvall O (2012) Dopaminergic neurons for Parkinson's therapy. Nat Biotechnol 30:56-58. CrossRef Medline

Mendez I, Sanchez-Pernaute R, Cooper O, Viñuela A, Ferrari D, Björklund L, Dagher A, Isacson O (2005) Cell type analysis of functional fetal dopamine cell suspension transplants in the striatum and substantia nigra of patients with Parkinson's disease. Brain 128:1498-1510. CrossRef Medline

Niwa H, Miyazaki J, Smith AG (2000) Quantitative expression of Oct-3/4 defines differentiation, dedifferentiation or self-renewal of ES cells. Nat Genet 24:372-376. CrossRef Medline

Nunes I, Tovmasian LT, Silva RM, Burke RE, Goff SP (2003) Pitx3 is required for development of substantia nigra dopaminergic neurons. Proc Natl Acad Sci U S A 100:4245-4250. CrossRef Medline

Olanow CW (1999) A rational approach to the treatment of early Parkinson's disease. Parkinsonism Relat Disord 5:217-220. CrossRef Medline

Olanow CW, Brin MF, Obeso JA (2000) The role of deep brain stimulation as a surgical treatment for Parkinson's disease. Neurology 55:S60-S66. Medline

Oueslati A, Sgambato-Faure V, Melon C, Kachidian P, Gubellini P, Amri M, Kerkerian-Le Goff L, Salin P (2007) High-frequency stimulation of the subthalamic nucleus potentiates L-DOPA-induced neurochemical changes in the striatum in a rat model of Parkinson's disease. J Neurosci 27:2377-2386. CrossRef Medline

Pearce RK, Heikkila M, Linden IB, Jenner P (2001) L-dopa induces dyskinesia in normal monkeys: behavioural and pharmacokinetic observations. Psychopharmacology (Berl) 156:402-409. CrossRef Medline

Perrier AL, Tabar V, Barberi T, Rubio ME, Bruses J, Topf N, Harrison NL, Studer L (2004) Derivation of midbrain dopamine neurons from human embryonic stem cells. Proc Natl Acad Sci U S A 101:12543-12548. CrossRef Medline

Thompson L, Barraud P, Andersson E, Kirik D, Björklund A (2005) Identification of dopaminergic neurons of nigral and ventral tegmental area subtypes in grafts of fetal ventral mesencephalon based on cell morphology, protein expression, and efferent projections. J Neurosci 25:64676477. CrossRef Medline

Tohyama T, Lee VM, Rorke LB, Marvin M, McKay RD, Trojanowski JQ (1992) Nestin expression in embryonic human neuroepithelium and in human neuroepithelial tumor cells. Lab Invest 66:303-313. Medline

Ye W, Shimamura K, Rubenstein JL, Hynes MA, Rosenthal A (1998) FGF and Shh signals control dopaminergic and serotonergic cell fate in the anterior neural plate. Cell 93:755-766. CrossRef Medline 